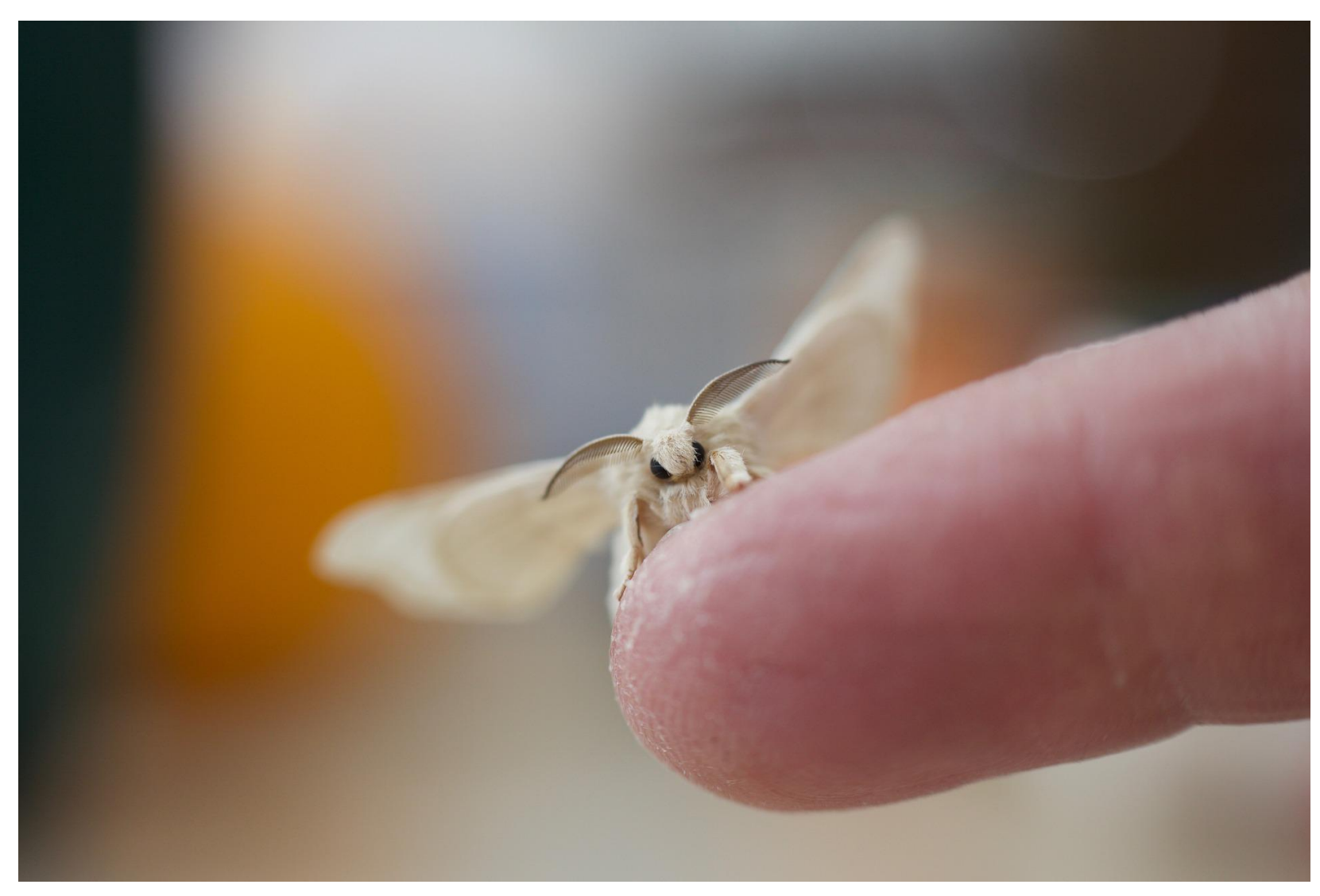

\title{
Silk production: global scale and animal welfare issues
}

$\underline{\text { Summary and key takeaways }}$

Introduction

Industry background

Description of practices

Potential welfare concerns

Rearing issues

$\underline{\text { Slaughter issues }}$

Industry scale 
$\underline{\text { Potential interventions }}$

Historical advocacy on silk issues

Hygiene improvements

Silk bans

Promoting silk alternatives

$\underline{\text { Consumer advocacy against silk use }}$

Areas for further research

\section{Conclusion}

Acknowledgements

Appendix

Scale estimate methodology

Potential issues in this estimate

Supporting documents

\section{Citations}

\section{Summary and key takeaways}

- At least 420 billion to 1 trillion silkworms are killed annually to produce silk.

- While only 61 billion to 170 billion of these worms die due to diseases and pests, diseases cause up to $99 \%$ of the cumulative days of potentially negative experiences I identified on farms, (with the remaining $1 \%$ caused by slaughter).

- This suggests that research to inform the prioritization of the silk industry for animal advocates ought to focus on the sentience of silkworms, not pupating silk moths, as has usually been assumed.

- Campaigns to ban silk or stop its sale at retail locations are plausibly the most promising avenue for animal advocates to reduce silk production, therefore reducing the days of potentially negative experiences caused by diseases on silk farms. Developing and promoting alternative silks may also be promising as an intervention. 
- I think that while there are promising interventions to reduce the suffering of silkworms, marginal resources in the insect space might be better spent in other areas, such as reducing the painfulness of pesticides, reducing the number of insects farmed for animal feed, and reducing the harms of cochineal farming.

- That being said, given the scale of silk farming, advocacy on this issue could plausibly be highly cost-effective when compared on a species-neutral basis to interventions to reduce vertebrate farmed animal suffering.

\section{Introduction}

The production of raw silk (called sericulture) typically uses the cocoons of Bombyx mori, the domesticated silk moth. Silk moths were domesticated around 5,000 years ago in China, and the yield from domestic silk moths is around 10 times that of their wild cousins.

To produce silk, worms are grown on mulberry leaves. After they cocoon, they are typically killed by being boiled alive or baked. Some cocoons are partially or wholly not fit for producing silk (referred to as "unreelable"), while others are reeled into thread, and used to produce textiles and other goods.

This report briefly describes the practices of the silk industry, with a special focus on practices that seem most likely to have negative animal welfare consequences. It also includes an estimate of the scale of the industry in order to facilitate charitable cause prioritization work for animal advocates. Finally, it discusses some efforts that have been made to reduce silkworm suffering, and discusses charitable interventions that might be effective in achieving these aims. Note that this report does not address silkworm sentience in any detail, and for the purposes of this report, silkworms are assumed to have valenced experiences. However, this position is neither one of consensus in the scientific community, nor a particularly deeply researched question, and shouldn't be taken for granted when using this report. For further research in this area (though not on silkworms specifically), see Rethink Priorities' exploration of invertebrate sentience. 


\section{Industry background}

\section{Description of practices}

Today, the major silk producing countries are China (around $80 \%$ of global production in 2017), India (around 18\%), and Uzbekistan (under 1\%), though at least 22 countries produce some amount of silk (INSERCO 2019). Also notably, data produced by industry group INSERCO and the FAO seem to disagree in their overall estimate of silk production by country. Silk production seems to vary widely year-over-year, so while the order of these countries remains fairly consistent, total production percentage might shift dramatically.

There are a handful of non-Bombyx mori silks produced, such as Tussar silk made with cocoons of moths from the genus Antheraea, or Eri silk, produced from Samia ricini caterpillars. However, mulberry-fed Bombyx mori silk seems to be the majority of silk produced, making up around 70\% of Indian production (The Economic Times 2019). In China, the data are less clear, but it seems like non-Bombyx mori silk production is less than $10 \%$ of all production ( $\mathrm{Wu} 2017$ ). I believe that historically, Chinese wild silk production might have been much higher (Peigler 1993), leading to some of the lack of clarity in the data today. While much of the non-Bombyx mori silk is produced from wild or semi-wild insects, this research focuses on the production of farmed and mulberry-fed Bombyx mori silkworms. However, slaughter methods described and the overall scale estimates should apply to essentially all silkworms (with the notable exception of Ahimsa silk slaughter, which is described separately).

To begin a mulberry silk crop (the most common food fed to silkworms), a female moth lays 300 to 400 eggs, and dies shortly after. Eggs incubate for around 10 days before hatching into approximately 0.25 inch worms. Larvae are kept in boxes on layers of gauze, and are fed chopped mulberry leaves. Worms feed for approximately six weeks

prior to cocooning. Over this period, they typically molt around four times, and grow to around three inches long, and 10,000 times their birth weight. They consume around 50,000 times their birth weight in mulberry leaves over this six week period (Agricultural Holdings International 2018). 
After around six weeks, the silkworms attach themselves to a fixed spot (in the wild this would be a branch, but in captivity it is typically a frame in a rearing house). It takes three to eight days for a silkworm to form a full cocoon. The silkworm releases a fluid called fibroin, which hardens in the air into a continuous filament, typically 1,000 to 3,000 feet long. The silkworm will rotate its body up to 300,000 times during these few days as it spins its cocoon (Agricultural Holdings International 2018). See this video for a timelapse of the process.

Silkworms that survive through cocooning begin to pupate and transform into moths. These moths release an enzyme that breaks through the filaments and creates a hole so the moth can emerge. If this occurs, the silk thread, which is wound up thousands of times, will be split into hundreds or thousands of pieces of varying length, significantly decreasing its commercial value and usefulness. To prevent this breakage, after the cocoons are fully formed the pupating animal is typically killed by boiling or heating the cocoon, which also makes it easier to reel the threads (Agricultural Holdings International 2018). Notably, future farm techniques might prevent silkworms from emerging at all, and the industry seems to be exploring these technological developments to improve reelability. Because silkworms move their bodies through hydrostatic pressure, if they get injured, movement would cause significant loss of bodily fluids, resulting in death. So, silkworms reactively paralyze themselves when injured. Researchers have recently developed a method to force silkworms to paralyze themselves in the cocoon, preventing them from emerging and breaking the silk threads. This would also allow silk to be reeled more precisely on farms, increasing yields significantly (Mortimer et al. 2013).

The thread is further processed, but since this doesn't involve animals, it is outside the scope of this report. However, it is worth noting that some cocoons are allowed to mature and hatch in order to facilitate the breeding of the next generation of silkworms. And, after the silkworms are killed, cocoons are assessed for their "reelability." A cocoon might be considered unreelable if the moth was able to pierce it, if it wasn't well formed, or if it received some other kind of damage. Many cocoons have varying reelability where they might be partially damaged, or split into many threads, decreasing their value (Lee 1999). 


\section{Potential welfare concerns}

\section{Rearing issues}

Disease seems to be a fairly significant cause of silkworm mortality, killing between $10 \%$ and $47 \%$ of worms depending on the country. The country-to-country variation seems to be due to a combination of practices, disease prevalence, and environmental conditions. These high death rates suggest that disease reduction is potentially an area where improvements in conditions could not only improve silkworm welfare, but potentially could significantly decrease the number of animals killed by the industry (though this could reduce costs, potentially increasing demand for silk in the long-run). The four most common diseases are flacherie, grasserie, muscardine and pebrine. These diseases, which range from bacterial to viral to fungal, all cause death, from within a few days to over ten days. Disease symptoms vary, but include loss of appetite, irregular molting, or other unusual behavior. Most diseases are treated through heavy applications of disinfectant, which themselves have unclear effects on silkworm welfare. It seems as though antibiotics may also be occasionally used (Nayak et al. 2006). In India, around $57 \%$ of disease loss deaths are due to flacherie, $34 \%$ grasserie, $2.3 \%$ pebrine, and $0.5 \%$ muscardine. Disease loss is more common in summer and autumn than in winter and spring (Tayal and Chauhan 2017).

Pests are less common than diseases in silkworm farms, but the most common are uzi flies and dermestid beetles. Uzi flies lay eggs at the junctions between body segments on silkworms, which hatch after two to three days. Uzi fly maggots bore into the silkworms, and feed on their flesh, before boring out after around seven days, killing the silkworm. Dermestid beetles feed on cocoons on farms, both during pupation, and after the pupa is killed by the producer. If they feed on a cocoon during putation, it typically kills the silk pupa (Tayal and Chauhan 2017).

\section{Slaughter issues}

The most common method of silkworm slaughter is to boil cocoons before the silkworm fully pupates and breaks the cocoon. This means that silkworms are killed as pupae, during their metamorphosis from larval to adult state as a silk moth. 
Pupation varies from species-to-species, but basically involves large amounts of tissue breaking down and reforming. This has led to some myths of moth and butterfly pupae being "goop" inside their cocoons, but this is inaccurate. Some organs and cells remain intact in some species, and notably, larval neurons survive this process in fruit flies (Lee et al. 1999). Some species of fly and moth have been found to retain olfactory memories across metamorphosis, though this doesn't seem to have been studied in silkmoths. This has been attributed to the survival of parts of the nervous system during pupation, though specific evidence for why olfactory memories survive has not been found (Blackiston et al., 2008, Tully et al. 1994). If aspects of the nervous system survive through pupation, and if silkworms and moths have the capacity for pain, this might be taken as very weak evidence that the boiling of silk pupae is painful, though the research in this space is by no means comprehensive, and none of it has been done specifically on silk pupae. It is also notable that some researchers have argued that the destruction of the nervous system is complete enough during pupation that the appearance of memory retention during metamorphosis might actually be due to genetic or other factors (Barron 2001). It also is worth noting that since the nervous system breaks down and reforms to at least some extent during pupation, the timing of slaughter might be an important consideration in assessing the harms of slaughter, since the nervous system might be in varying levels of intactness over the course of pupation.

Currently, the evidence that silkworms suffer during slaughter is extremely limited, so it is hard to come to a definitive position on the welfare consequences of boiling silkworms specifically. Fortunately, future research might be better able to answer this uncertainty - new imaging techniques have significantly improved our ability to understand what happens to insect bodies during pupation (Lowe et al. 2013).

\section{Industry scale}

\begin{tabular}{|l|r|r|r|r|}
\hline Type & Deaths & $\begin{array}{r}\text { Population } \\
\text { alive on } \\
\text { average }\end{array}$ & $\begin{array}{r}\text { Days of potentially } \\
\text { negative experience } \\
\text { (PNE) per year }\end{array}$ & $\begin{array}{r}\text { Percent of total } \\
\text { identified PNE per }\end{array}$ \\
& & year \\
\hline
\end{tabular}




\begin{tabular}{|l|r|r|r|r|}
\hline $\begin{array}{l}\text { Reelable } \\
\text { cocoons }\end{array}$ & $240 \mathrm{~B}-400 \mathrm{~B}$ & $25 \mathrm{~B}-42 \mathrm{~B}$ & $1.4 \mathrm{~B}-3 \mathrm{~B}$ & $0.17 \%-1.3 \%$ \\
\hline $\begin{array}{l}\text { Unreelable } \\
\text { cocoons }\end{array}$ & $80 \mathrm{~B}-520 \mathrm{~B}$ & $8.7 \mathrm{~B}-51 \mathrm{~B}$ & $530 \mathrm{M}-3.7 \mathrm{~B}$ & $0.11 \%-0.86 \%$ \\
\hline $\begin{array}{l}\text { Disease and } \\
\text { pest loss }\end{array}$ & $61 \mathrm{~B}-170 \mathrm{~B}$ & $4.1 \mathrm{~B}-13 \mathrm{~B}$ & $180 \mathrm{~B}-1.3 \mathrm{~T}$ & $98.1 \%-99.7 \%$ \\
\hline Overall & $420 \mathrm{~B}-1 \mathrm{~T}$ & $41 \mathrm{~B}-99 \mathrm{~B}$ & $180 \mathrm{~B}-1.3 \mathrm{~T}$ & \\
\hline
\end{tabular}

I estimate that in 2017 (the most recent year comprehensive data is available) that between 420 billion and 1 trillion silkworms were killed or died due to disease on silk farms. I further estimate that silkworms lived a total of between 15 trillion and 37 trillion days on farms, of which at least 180 billion to 1.3 trillion days involved some degree of potentially negative experience, such as being slaughtered or suffering from a disease (note that slaughter only counts as a small fraction of day in this estimate, since it only lasts a few minutes). My estimate divides cocoons as "reelable" and "unreelable." To approach building an estimate, I divided these into distinct categories. However, in reality, cocoons fall in a spectrum along this line, varying in reelability. I simply took the overall percentage of reelability across all cocoons, and split cocoons into two categories. This should result in an accurate estimate of the total number of cocoons used. See the appendix for further discussion of the methodology used in this estimate, and possible issues in its design.

\section{Potential interventions}

Looking at the potentially negative experiences in silkworm lives, it seems possible that the vast majority (up to $99 \%$ ) of days of suffering on farms is due to diseases and pests, and not due to the slaughter itself. Even if the slaughter is painful, which is not currently borne out in available evidence, it is likely a very brief experience, lasting just a few minutes, or around $0.02 \%$ of the average silkworm's life, compared with disease taking up around $70 \%$. So, any intervention to reduce silkworm farming will most likely primarily be benefiting silkworms who will die on farms due to disease loss. It's also worth noting that silkworms who survive to slaughter could live otherwise positive 
lives. While there isn't much research into silkworm quality of life, they mostly seem to live on beds of mulberry leaves eating prior to slaughter, with minimal disturbance that might lead to stress. However, a caveat is that research into nonlethal disease and injury on silk farms is basically nonexistent, since it is typically unrelated to commercial success.

\section{Historical advocacy on silk issues}

Advocacy on silk issues has been limited within the animal welfare community, and primarily has focused on securing bans of silk sales. Organizations like PETA have run somewhat successful campaigns, mostly in the US, to secure retailer commitments to stop using silk (Toliver 2018). Some major brands, including the fashion retailer ASOS, have pledged to no longer sell silk (Bain 2018).

In 2019, Material Innovation Initiative was founded, and as part of its mission it advocates for and supports the development of alternatives to silk products, with the goal of replacing silk use with non-animal alternatives (Vegan Startup Podcast 2020).

Finally, alternative silk products, such as Ahimsa silk, have been promoted as animal-friendly. These products purport to use only cocoons from which a moth has already emerged, so no death supposedly occurs in the production process (though deaths from disease would still likely occur). Beauty Without Cruelty (BWC) has reportedly visited Ahimsa silk farms, and noted that most moths that hatch from these cocoons are not fit to fly, and die immediately. It's unclear why this might be, but it is possible that the breeds of silk moths used at the facility they visited are highly domesticated, and this early death is a result of that breeding. Also, BWC notes that it requires many more Ahimsa silkworms to create an equivalent amount of silk as conventional silk, because fewer cocoons are reelable (Beauty Without Cruelty 2021). This is supported in industry documentation that claims that pierced cocoons are less commercially viable (Agricultural Holdings International 2018). It seems that Ahimsa silk is not necessarily a more humane alternative, unless one was only concerned about suffering during slaughter, which doesn't seem to be the main source of suffering in silk worms. 


\section{Hygiene improvements}

Since a significant number of silkworms are killed by disease, it seems possible that hygiene improvements, such as disinfecting areas between silkworm batches could result in significantly fewer deaths, and significantly fewer days of suffering (in particular because many diseases and pests impacting silkworms take several days to cause death).

However, it seems that most farms already do highly intensive disinfecting routines, in part because disease loss is commercially expensive (Tayal and Chauhan 2017). So it is possible that further campaigns to improve hygiene won't result in significant reductions in disease loss.

An additional concern is that hygiene campaigns, by reducing deaths prior to slaughter, could decrease silk prices. If this resulted in greater demand for silk, it might result in more silkworms being produced overall.

\section{Silk bans}

Campaigns to secure bans on silk on a policy level or to secure commitments from retailers to not purchase silk have been successful in the past, and could be expected to directly result in fewer silkworms dying due to disease, as overall demand on farms would be reduced. One notable reason silk bans and commitments to end the use of silk have been successful is that the silk industry frequently is accused of having violated human rights, through human health issues, child labor abuses, and slavery on factories (Human Rights Watch 2003). Many campaigns have focused on these issues, instead of on silkworm welfare. However, the commitment from ASOS was based on an animal welfare rationale.

\section{Promoting silk alternatives}

Some organizations, like Material Innovation Initiative, work to promote alternatives to silk. If these alternatives are used instead of silk, they would result in a reduction of overall silk production. It seems plausible that silk alternatives, if they were cheaper and more versatile than animal silk, could replace many commercial and industrial uses 
of silk (it's used in tire manufacturing and medical equipment manufacturing, among other industries). However, it is less clear that cheap silk alternatives would replace retail silk fashion to a large degree. It's possible these would just be used as an alternative to other non-animal fabrics, such as cotton. Proponents of these alternatives argue that the environmental benefits of silk alternatives provide a compelling reason for them to replace animal silk directly (Vegan Startup Podcast 2020).

\section{Consumer advocacy against silk use}

Convincing consumers to purchase less silk is another route that might reduce the deaths caused by silk production. The existing market for Ahimsa silk in India suggests that at least some consumers are motivated by animal welfare reasons to stop buying silk. There also seem to be good human-focused reasons to not use silk, mentioned under Silk bans above (though these should be genuinely campaigned against, and not used only instrumentally by animal welfare advocates). These factors suggest that progress on silk issues through consumer advocacy might be effective for some consumers. Since Ahimsa silk purchases have demonstrated an interest in silkworm welfare, one area to start might be convincing these consumers that Ahimsa silk does not significantly reduce the harms of silk farming, and urge them to switch to non-silk alternatives.

\section{Areas for further research}

\section{Are most deaths in unreelable cocoons occurring prior to slaughter?}

My model assumes that the deaths of silkworms who produce fully or partially unreelable cocoons are dying during slaughter. It is possible that some of these deaths are occurring prior to slaughter during the cocooning phase, and more information on these deaths might help clarify how large an area of concern these deaths are.

\section{What are the impacts of disinfectants used to treat disease on animal welfare?}

Disease on silk farms is typically treated through the application of various disinfectants. These disinfectants could presumably impact the welfare of silkworms on farms. Further research into the effects of disinfectant use might help clarify how treatment impacts animal welfare. 


\section{What are the lives of silk moths raised for breeding purposes like?}

Some silkworms are raised to adulthood for breeding. Further research into the scale and welfare of these animals would be helpful for assessing the overall harms of the industry.

\section{What is a silkworm's capacity for valenced experiences?}

Since most of the suffering on silk farms seems to come from animals dying of disease on farms prior to slaughter, research into silkworms' moral personhood ought to focus on silkworms themselves, and not pupae who are slaughtered for cocoons.

\section{How would the public respond to silk campaigns?}

Prior to beginning campaigns related to silk, research that helps clarify how the public might respond to these campaigns would improve messaging and the effectiveness of these campaigns. There is little information on whether or not the general public supports silk bans, for example, so research into this could inform future campaigns.

\section{Conclusion}

Overall, silk production seems to have pressing animal welfare concerns that animal advocates ought to work to address, especially by lowering the number of animals that die slow, and possibly painful deaths, from diseases and pests on silk farms.

However, I believe that given its relatively small scale (compared to other invertebrate industries), addressing silk production is likely less urgent than other areas I and others have reviewed previously. My current belief is that the most urgent priorities of invertebrate welfare advocates ought to be reducing the painfulness of pesticides, reducing the harms of farming insects for animal feed, and reducing the suffering of cochineals. I think it is possible that other areas that have not been reviewed are as important as these priorities (though it seems likely no industries match the scale or harms of pesticide use). That being said, advocacy on silk might possibly be very cost-effective on a species-neutral basis compared with vertebrate farmed animal advocacy. Additionally, if the silk industry grows significantly in the next few decades, it might be a higher priority area to work in. 


\section{Acknowledgements}

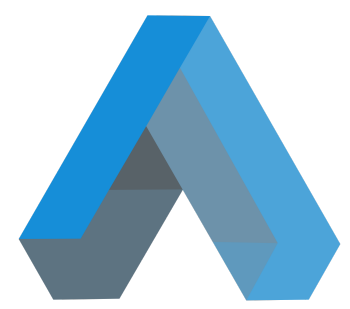

This research is a project of Rethink Priorities. It was written by Abraham Rowe. Thanks to Jason Schukraft, Daniela Waldhorn, Saulius Simcikas, and Neil Dullaghan for helpful feedback. If you like our work, please consider subscribing to our newsletter. You can see more of our work here.

\section{Appendix}

\section{Scale estimate methodology}

I based my estimate primarily on production figures published by the Food and Agriculture Organization of the United Nations. Prior to 2014, the FAO produced estimates of the weight of global production of both reelable cocoons produced, and the raw silk produced from those cocoons. Since 2014, they've only published estimates of the weight of reelable silk produced.

Lee 1999 estimates typical wet cocoon weight to be between $1.5 \mathrm{~g}$ and $2.5 \mathrm{~g}$. This implies that in 2017, 240 billion to 400 billion fully reelable cocoons were required to produce that year's silk output. A further 80 billion to 520 billion cocoons were required to produce the harvest because not all cocoons are fully reelable, and a further 61 billion to 170 billion silkworms died due to disease or pests. 


\section{Potential issues in this estimate}

I verified my estimate by comparing what the implied annual raw silk production my model predicted for 2017 with figures produced by INSERCO, a UN silk advocacy organization. The average production for 2017 my model predicted was approximately 177,978 tonnes, while INSERCO estimated actual production to be 177,507 tonnes, suggesting that my model was highly accurate, and also makes me highly confident that silk farming has become increasingly efficient in the last 70 years. In 1999, the FAO reported that raw silk production was $12 \%-20 \%$ of the whole reelable cocoon (Lee 1999). However, looking at the historical FAO production figures, it becomes clear that these figures are now inaccurate. Since 1961, raw silk production has increased from $15 \%$ of cocoon (by weight) to around 30\% in 2014 (supporting document 2). If I attempt to calculate raw silk production using Lee's figures, my estimate is very inaccurate, while if I use a range reflecting more recent data, my estimate almost exactly predicts INSERCO's production estimates.

I also attempted to verify my estimate by calculating the implied number of silkworms required per pound of raw silk produced - a figure that has been anecdotally reported several times. My model suggests that this figure is somewhat lower than previously reported figures - 1100 to 2600 worms per pound of raw silk. Others have estimated that up to 6000 worms are used per pound of raw silk (Beauty Without Cruelty 2021, Agricultural Holdings International 2018, Barwick 2015). My best guess is that there are a few factors contributing to this difference. The sources cited for figure are anecdotal, and stem from only 1 or 2 producers making casual estimates (Beauty Without Cruelty 2021, Barwick 2015). However, at least one prominent academic estimate is fairly close to mine - estimating around 1400 worms per pound, while my estimate is 1700 on average, although it is unclear if this academic estimate includes worms killed by disease on farms (Fritz and Cant 1986). Finally, at least one prominently published estimate was made by an Ahimsa silk producer, which uses a different breed of silkworm that may produce less silk per cocoon, leading to the discrepancy (Barwick 2015). If these other larger figures are more accurate than mine, my estimate of how many silkworms are killed for silk production would almost certainly be an underestimate. 


\section{Supporting documents}

Supporting document 1 - Global silkworm production estimate (2017)

Supporting document 2 - Silk raw/reelable ratio (1961-2014)

\section{Citations}

Agricultural Holdings International. (2018). Silkworm Farming. https://www.ahi-intl.farm/post/silkworm-farming

Aishwariya, S. (2020). Interesting dimensions of Ahimsa silk (Vegan silk). The Indian Textile Journal, 108-112.

https://www.researchgate.net/publication/340279882_Interesting_dimensions_of _Ahimsa_silk_Vegan_silk

Bain, M. (2018). ASOS is banning silk, but is it really unethical to wear? Quartz. https:/qz.com/quartzy/1309227/asos-is-banning-silk-but-is-it-really-unethical-towear/

Barron, A. B. (2001). The Life and Death of Hopkins' Host-Selection Principle. Journal of Insect Behavior, 14(6), 725-737. https://doi.org/10.1023/a:1013033332535

Barwick, E. M. (2015). Is Silk Vegan? How Is Silk Made? Bite Size Vegan. http://bitesizevegan.org/ethics-and-morality/is-silk-vegan-cruel/

Beauty Without Cruelty. (2021). So-called "Ahimsa Silk." http://bwcindia.org/Web/Awareness/LearnAbout/SocalledAhimsaSilk.html Blackiston, D. J., Silva Casey, E., \& Weiss, M. R. (2008). Retention of Memory through Metamorphosis: Can a Moth Remember What It Learned As a Caterpillar? PLoS ONE, 3(3), e1736. https://doi.org/10.1371/journal.pone.0001736

Food and Agriculture Organization of the United Nations. (2017). Silk Production Data. FAOSTAT. Retrieved 2021, from http://www.fao.org/faostat/en/\#search/silk

Fritz, A., \& Cant, J. (1986). Consumer Textiles. Oxford University Press.

Human Rights Watch. (2020). Child Slaves Abandoned to India's Silk Industry. https://www.hrw.org/news/2003/01/23/child-slaves-abandoned-indias-silk-indust ry

INSERCO. (2019). Statistics. https://inserco.org/en/statistics 
Lee, T., Lee, A., \& Luo, L. (1999). Development of the Drosophila mushroom bodies: sequential generation of three distinct types of neurons from a neuroblast. Development, 126, 4065-4076. https://dev.biologists.org/content/126/18/4065.short

Lee, Y. W. (1999). Silk Reeling and Testing Manual. Food and Agriculture Organization of the United Nations.

Lowe, T., Garwood, R. J., Simonsen, T. J., Bradley, R. S., \& Withers, P. J. (2013). Metamorphosis revealed: time-lapse three-dimensional imaging inside a living chrysalis. Journal of The Royal Society Interface, 10(84), 20130304. https://doi.org/10.1098/rsif.2013.0304

Mortimer, B., Holland, C., \& Vollrath, F. (2013). Forced Reeling of Bombyx mori Silk: Separating Behavior and Processing Conditions. Biomacromolecules, 14(10), 3653-3659. https://doi.org/10.1021/bm401013k

Nayak, P. (2006). Influence of antibiotic on feed conversion efficiency of mulberry silkworm (Bombyx mori L.). Animal Biology, 56(1), 13-22. https://doi.org/10.1163/157075606775904731

Peigler, R. S. (1993). Wild Silks of the World. American Entomologist, 39(3), 151-162. https://doi.org/10.1093/ae/39.3.151

Tayal, M. K., \& Chauhan, T. P. S. (2017). Silkworm Diseases and Pests. Industrial Entomology, 265-289. https://doi.org/10.1007/978-981-10-3304-9_9

The Economic Times. (2019). Raw silk production increased by 10.52 percent: Smriti Irani. https://economictimes.indiatimes.com/industry/cons-products/garments-/-textile s/raw-silk-production-increased-by-10-52-per-cent-smriti-irani/articleshow/70290 395.cms

Toliver, Z. (2018, August 22). 3,000 Animals Die for 1 Pound of Silk-Reasons Not to Rock It. PETA. https://www.peta.org/blog/is-silk-vegan/

Tully, T., Cambiazo, V., \& Kruse, L. (1994). Memory through metamorphosis in normal and mutant Drosophila. The Journal of Neuroscience, 14(1), 68-74. https://doi.org/10.1523/jneurosci.14-01-00068.1994

Vegan Startup Podcast. (2020). Future of Fabrics - Material Innovation Initiative. https://bitesociety.com/blogs/news/future-of-fabrics-material-innovation-initiativ e

Wu, Y. (2017). Studying silkworms honors ancient tradition. China Daily. https://www.chinadaily.com.cn/china/2017-06/12/content_29707504.htm 